\title{
A New Mind-set for Exchange Rates
}

\author{
STEPHEN GRENVILLE ${ }^{1}$
}

\section{The Old Mind-set}

Following the breakdown of the Bretton-Woods system of fixed exchange rate in the early 1970s, many countries chose to hand over the exchange-rate determination to the financial markets, with a free float. That a free float would deliver the optimal result was presumed by many practitioners and nearly all academics. Harry Johnson (1972) promised that "A freely flexible exchange rate would tend to remain constant so long as underlying economic conditions (including government policies) remain constant; random deviations from the equilibrium level would be limited by the activities of private speculators."

Things turned out very differently, with large fluctuations seemingly unconnected to any change in the 'fundamentals'. The US dollar fluctuated by more than 30 per cent in the mid 1980s. The Japanese yen moved over a range from almost 150/US\$ to 80/US\$ within a space of three years in the mid 1990s. Smaller currencies such as the Australian dollar fluctuated even more widely. Emerging countries fared worse still, with Latin America in general crisis in the 1980s, Mexico again in 1994, East Asia in 1997 and Russia in 1998. This didn't seem to fit with the idea that 'fundamentals' would change slowly and arbitrageurs would smooth the rate over time. It was not just a matter of short-term volatility (which might not do much harm): as well, there were large and persistent misalignments with sudden readjustments, even for the largest countries with deep and mature financial markets.

Despite this, the faith in the magic of the market - in the free float — remained. Even for emerging countries with immature financial markets, the International Monetary Fund's message was to float and let the market sort it out, with minimal intervention and no capital controls. Fixed rates against the US dollar were seen as the major cause of the Asian crisis of 1997 and the remedy was to float freely.

1 The Lowy Institute, stephengrenville@hotmail.com. 
Two factors have opened up this debate again. First, the Global Financial Crisis has highlighted the imperfections of the market's price-discovery process. ${ }^{2}$ No longer will any debate be stopped in its tracks by making the point: 'You don't think you know better than the market, do you?'

Second, there is now a fair bit of accumulated evidence that what is pejoratively called a 'dirty' float is not only feasible, but can work pretty well. ${ }^{3}$ Few countries have practised the benign neglect implied by a pure free float. A number of countries have run successful exchange-rate regimes which rely on a free market float much of the time, but use market intervention (sometimes quite substantial) when the market doesn't seem to be delivering a sensible answer. Australia provides one of the clearest examples of this. Of course, it is difficult to convince a sceptical audience that the substantial intervention altered the course of the exchange rate: we don't know for sure what would have happened without the intervention. But in the first 20 years of the float, the RBA made a profit of more than $\mathrm{A} \$ 5$ billion through its intervention (Becker and Sinclair 2004). Even Milton Friedman (1953) accepted that if intervention was profitable, there is a powerful presumption that it was stabilizing.

Still the IMF staff remained unconvinced. A working paper detailing the Australian experience concluded: 'The apparent success of intervention in affecting the level of the Australian dollar appears to have come at the expense of increasing volatility of exchange rate movements.' ${ }^{4}$

Australia was not alone in profitable intervention. Japan had similar success (Ito 2002) but, following the adage that 'it is the spouting whale that is harpooned', it has kept a low profile on its intervention.

Still, the received academic wisdom is that sterilised intervention has little or no effect. Simple theoretical models often assume perfect substitutability of assets in different currencies. Empirical work often relied on a heterogeneous mixture of examples. Some intervention episodes, such as the 1992 defence of sterling, reflected politics more than economics and were foredoomed. Certainly, there were enough examples of policy failure where the authorities had attempted

2 It is tempting to say that the GFC highlighted serious flaws in the Efficient Markets Hypothesis. The EMH, taken by itself, says no more than that the market price has already taken account of all publicly available information. But its name seemed to promise more than this near-platitude. Combined with the idea that people are rational and that market participants face risk (which can be measured by probabilities) rather than uncertainty, something more loosely styled 'efficient markets' seemed to imply that the price-discovery process would be optimal.

3 See Sarbo and Taylor (2001).

4 Edison, Cashin and Liang (2003). Of course the volatility this paper is testing is daily volatility, irrelevant to the question of stabilization over the course of the cycle. Seeing the profit made by this intervention, some argue that it needs to be discounted for risk. But the usual measures of risk — short-term volatility — are not relevant for long-term position-taking, where the position will not be unwound to meet some short-term liquidity need. The 'risk' for a long-term holder is that the position will be eventually unwound at a loss, and this is fully captured by the profit calculation. 
to defend disequilibrium rates. Rather than examine cases where intervention worked well and try to analyse just why it was effective in these cases, these futile interventions were often regressed together with the successes, drawing the general conclusion that intervention was futile at best and harmful at worst.

At the same time that studies were showing intervention to be futile, the best academics also noted something that should have shaken confidence in our understanding of exchange rates. In the early 1980s, Meese and Rogoff (1983) found that no fundamentals-based model of the exchange rate (whether based on purchasing power parity, trade flows, capital flows or interest differentials) could beat the 'random walk' (that today's estimate of the exchange rate is the best estimate of the future rate). In other words, no model could offer any help at all in predicting the path of the exchange rate. Extensive testing in the ensuing quarter-century has left this conclusion unaffected over the short run, although some models fare better at explaining longer-term exchange-rate tendencies (Rogoff 1999).

This amazing result might have taken researchers down either of two paths. It might be that the models were accurately capturing where the equilibrium exchange rate should be and the market was not delivering this answer. Or it could send researchers to develop a theory that could explain the behaviour of the exchange rate. Largely, the latter path was chosen. Researchers worked hard to fit the real world into the EMH, explaining the exchange rate in terms of 'time-varying risk' and other deus ex machina devices.

A more fruitful line of analysis noted that not all market participants based their trading on economic fundamentals. Frankel and Froot (1986) hypothesised that the market comprised both 'fundamentalists' and 'chartists', and sometimes the chartists were dominant. But even those who accepted this hypothesis did not ask whether the policymakers could or should intervene when the chartists were in the ascendancy, taking the rate to non-equilibrium levels. The free market was still sacred, even when it was wrong.

A much smaller group (De Grauwe and Grimaldi 2006) worked on the intuitively plausible idea that while no-one had a precise idea of what the equilibrium exchange rate should be at any moment, it was more useful to think about equilibrium as lying within quite a wide range of 'rational beliefs' (that is, not inconsistent with the evidence). Not only did this explain why the actual market outcome might not correspond to the fundamental equilibrium, but it also explained why the rate could move sharply in response to trivial 'news'. When people are uncertain as to the right rate (and their 'model' of exchangerate formation has a wide margin for error), a random event can cause people to shift their view on what is the equilibrium exchange rate quite substantially and suddenly. 
But this range of rational beliefs is not enough, in itself, to explain the magnitude of the departures from equilibrium. The more extreme movements can only to be explained in terms of market dynamics and endogenous risk. Once the price starts to move, portfolio and accounting constraints force market participants to cut their positions in currencies, even when they believe that the price is already below the equilibrium and will revert in due course.

Why doesn't arbitrage fix the problems? In practice, most arbitrageurs cannot actually take much risk. Very few institutions can hold an open FX position for long. Persistence is a problem for disequilibrium rates: as Keynes is said to have remarked, markets can remain irrational for longer than you can remain solvent.

\section{A New Mind-set}

If we accept that the market price is not always gravitating towards the equilibrium exchange rate, the policy mind-set can and should shift fundamentally, to focus on two questions. What is the equilibrium rate? Can intervention shift the actual rate towards this?

The first question poses a major challenge for policymakers. While a free-float regime does not require the policymakers to have any view at all as to the 'right' exchange rate, the new mind-set requires them to have a view on the equilibrium exchange rate. This is not easy (perhaps impossible) to do with precision, but the answer might well be in the form of a range reflecting the array of 'rational beliefs' (just as inflation targeting sees the acceptable inflation rate as a band rather than a single point).

The second question requires a similar shift in policy mind-set. Instead of assuming that the market has established the equilibrium rate (and therefore any intervention will take the actual rate away from its equilibrium), if the market rate is sub-optimal, this opens the possibility that successful intervention would take the rate towards equilibrium. Then the policy question is an operational one: does the policymaker have the means to shift the rate in the right direction?

This opens up a range of feasible exchange-rate regimes and policies, other than free floating. One approach to the equilibrium issue is the band/basket/crawl (BBC) regime suggested by Williamson (2008). The authorities announce a target band which defines the range in which they believe the equilibrium lies. This allows variation within this band but requires firm intervention at the edges of the band. If the market accepts the band as credible, speculators will not challenge the band (and might even support it: after all, just as the authorities don't know for sure what the 'right' rate is, neither do the speculators). The 
$\mathrm{BBC}$, of course, is in inflation-adjusted real terms and the 'crawl' of the band acknowledges the need for adaptation to the (implicitly slowly changing) fundamentals.

For those who (understandably) worry that countries may be too active in their intervention and will defend a non-equilibrium level for mercantilist reasons, an alternative regime is to establish an internationally endorsed 'reference range' and specifically renounce intervention within this range (a genuflection to the market and acknowledgment that the model is uncertain) but allow intervention once the band is breached.

Others (for example, Australia and Japan) have a more ad hoc approach, intervening when the market seems to be clearly misbehaving, usually only when the market has taken the rate to a clearly incorrect level, where the misalignment is more likely to be harmful.

Policymakers will have to consider that the equilibrium might be changing over time. It will also have a cyclical component. Some temporary departure from the longer-term fundamental equilibrium exchange rate (FEER) over the course of the cycle is desirable (and part of the transmission mechanism of monetary policy) as the exchange rate can usefully 'spill' excess demand into net imports.

The IMF itself has an internal committee which has been wrestling with the notion of the 'right' rate, although its two-fold objectives are carefully defined to avoid endorsing market intervention. The first purpose is to give countries warning if their exchange rate risks causing a crisis (for example, through excessive current-account deficits and too much foreign debt). The second purpose is directed at identifying exchange-rate 'manipulation' (that is, rates which were being held away from their equilibrium by policy, usually for mercantilist reasons) rather than providing a starting point for policy action to shift the actual rate towards its equilibrium. China is a case in point, although it has not been formally declared to be a 'manipulator'.

In the IMF's exchange-rate analysis there are three measures of 'equilibrium' - one akin to Williamson (based on the sustainability of the current account), one based on a macro-model and one depending on the sustainability of foreign debt (closely associated with the Williamson approach). The precise answers are not publicly available, and the routine write-up usually finds that the answers (which often differ significantly between the three methods) are all compatible with the actual rate.

At least at this stage, these attempts lack enough precision and have too many questions about methodology to be the basis of firm policy action, especially of a mechanistic nature. If they are to be the basis of serious discussion, the sensitivities (which at the moment stop the IMF from publishing the exact 
exchange rates which their methodology implies) need to be overcome. But this sort of analysis is the starting point of a new and better policy approach to exchange rates.

The doctrinal fixation with persuading countries to adopt a pure free float has distracted us for three decades from this practical operational task of identifying the equilibrium exchange rate (in terms of a range or central tendency) and devising effective intervention strategies. But the Fund position now seems to have shifted significantly. The Fund has abandoned the 'corner solutions' argument, which said that countries needed to be either rigidly pegged (like Hong Kong) or free floating. The previously infeasible middle ground is now judged to be viable (Gosh and Ostry 2009).

\section{The Challenge}

What is required now is a wider change in the mind-set. We should accept that, while the market is a powerful tool for the discovery of the equilibrium price that may well be right on average and most of the time, at times it goes awry. If this is accepted, then efforts to push the rate towards equilibrium can't be dismissed on the basis of principle or doctrine. It may be difficult to establish the equilibrium with accuracy, and the authorities may have imperfect instruments to influence the exchange rate (so they would not be aiming to achieve the FEER, only to move towards it). But this is a debate which should be joined, and it should be done in the open, without the inhibiting presumption that intervention is a sign of policy inadequacy.

The conceptual mind-set is simple enough: the policymakers should be trying to mimic the equilibrium exchange rate that a well-functioning market would produce. The theoretical attraction of a free-market floating solution was that the financial markets promised to deliver this. This would guard against policymakers attempting to impose their mistaken preconceptions or their mercantilist export-oriented priors on this. It falls down only because the market has shown itself unable to provide this price discovery, at least in a form that is consistent and stable over time. But the key point is that any intervention should be trying to mimic a well-functioning market, not override it to produce a non-equilibrium exchange rate. 'Active' policy must resist the temptation to use the exchange rate for some non-equilibrium purpose - for a mercantilist purpose or to hold the rate at some non-equilibrium level because change is politically unpalatable or harms certain vested interests. 
Will the authorities make mistakes in their interventions? Of course they will, just as they make mistakes with the other policy instruments. But principled inaction is not the answer: to claim innocence on the basis of inaction is no defence if a valid and beneficial policy is available.

There remains a further issue. While we noted that there have been very substantial and sustained shifts in exchange rates, even for countries with deep and mature markets such as Japan and Australia, these shifts seem to have caused few problems, at least as far as can be judged by complaints from those who might have been adversely affected. One curious stylised fact that coincides with the floating-rate period is that the pass-through to domestic inflation seems to have been either small or very slow. Thus the authorities have been prepared to see large downward shifts in the exchange rate without feeling the need to support the currency through higher interest rates. While elements in the tradable-good sector complain from time to time, developed economies seem to have adapted to these large swings in the exchange rate. This can't simply reflect widespread hedging, as the large cumulative external imbalances in both Japan and Australia must have left substantial foreign-exchange exposures. In any case, if exchange-rate changes don't have any effects, we might need to reexamine some core parts of international trade theory.

Thus the policy implications of this paper for the developed countries are small. Japan and Australia will presumably go on intervening, profiting from this intervention but without doing more then 'filling the troughs and lopping the peaks' of the path of the exchange rate over time.

Where this analysis has more practical policy force is with the emerging countries and the advice which the IMF gives to them. Here, the big swings in exchange rates are clearly disruptive. Both Indonesia and South Korea suffered large falls in their exchange rates during the GFC, even though their economies were not directly involved in the crisis. These exchange-rate falls posed a serious threat to financial stability. In both cases, the authorities intervened very substantially, and in both cases the fall was short-lived, justifying the intervention in terms of profitability, at least. Nevertheless, the IMF's reaction, in the case of Korea, was to persuade the authorities that future intervention should be limited to (irrelevant) 'smoothing and testing'. The new doctrine, as espoused by Gosh and Ostry, has not yet filtered down to the Fund's operational staff. It is within that institution that the greatest mind-set change is needed. 


\section{References}

Becker, C. and Sinclair, M. 2004, 'Profitability of Reserve Bank Foreign Exchange Operations: Twenty Years After The Float', Reserve Bank of Australia Research Discussion Paper RDP2004-06.

De Grauwe, P., and Grimaldi, Marianna 2006, The Exchange Rate in a Behavioral Finance Framework, Princeton, NJ: Princeton University Press.

Edison, H., Cashin, P. and Liang, H. 2003, 'Foreign exchange intervention and the Australian dollar: Has it mattered?', IMF Working Paper 03/99.

Frankel, J. A. and Froot, K. A. 1986, 'Understanding the US Dollar in the Eighties: The Expectations of Fundamentalists and Chartists' Economic Record 62: 24-38.

Friedman, M. 1953, 'The Case for Flexible Exchange Rates' in Essays in Positive Economics, Friedman M. (ed.), Chicago: Chicago University Press.

Gosh, A. and Ostry, J. 2009, 'Choosing an exchange rate regime', Finance and Development 46(4).

Ito, T. 2002, 'Is Foreign Exchange Intervention Effective? The Japanese Experiences in the 1990s', NBER Working Paper No. 8914, April.

Johnson, H. 1972, 'The Case for Flexible Exchange Rates' in Further Essays in Monetary Economics, Allen \& Unwin: London.

Meese, R. and Rogoff, K. 1983, 'Empirical Exchange Rate Models of the 1970s: Do They Fit Out of Sample?' Journal of International Economics 14: 3-24.

Rogoff, K. 1999, 'Monetary Models of Dollar/Yen/Euro Nominal Exchange Rates: Dead or Undead?' Economic Journal 109: F655-9.

Sarno, L. and Taylor, M. P. 2001, 'Official Intervention in the Foreign Exchange Market: Is It Effective and, If So, How Does It Work?' Journal of Economic Literature 39(3): 839-68.

Williamson, J. 2008, 'Exchange Rate Economics', Peterson Institute Working Paper 08/03, February. 